\section{RUI BARBOSA E A EDUCAÇÃO FÍSICA NOS PARECERES PARA O ENSINO PRIMÁRIO DE 1883: INFLUÊNCIAS E PROPOSIÇÕES}

\author{
RUI BARBOSA'S 1883 EXPERT OPINIONS ON PHYSICAL EDUCATION \\ IN PRIMARY SCHOOL: INFLUENCES AND PROPOSALS C己
}

RUI BARBOSA Y LA EDUCACIÓN FÍSICA EN LOS INFORMES PARA LA EDUCACIÓN PRIMARIA DE 1883: INFLUENCIAS Y PROPOSICIONES C己

doi' https://doi.org/10.22456/1982-8918.104923

\section{(iD) Fernando Resende Cavalcante* <fernandorcavalcante@hotmail.com>}

Gabriel Carvalho Bungenstab** <gabrielcarv@msn.com>

Ari Lazzarotti Filho*** <arilazzarotti@gmail.com>

\footnotetext{
*Universidade de Brasília. Brasília, DF, Brasil.

**Universidade Estadual de Goiás. Goiânia, GO, Brasil.

***Universidade Federal de Goiás. Goiânia, GO, Brasil.
}

Resumo: O objetivo do estudo foi identificar as influências e proposições para a Educação Física apresentadas por Rui Barbosa em seu parecer para o ensino primário. Os documentos analisados foram: o parecer intitulado "Reforma do Ensino Primário e várias instituições complementares da instrução pública", publicado em 1883 , e o decreto $n^{\circ} 7.247$, de 19 de abril de 1879. A pesquisa caracterizou-se como qualitativa, teve como teoria de orientação para as análises a Micro-história e utilizouse da técnica de Análise de Conteúdo. Podem-se identificar cinco influências: os gregos antigos; os fisiologistas; as nações modernas; os pensadores da educação; e os pensadores da ginástica. No que concerne às proposições, identificaram-se: a ginástica para ambos os sexos; a criação de uma seção de ginástica nas escolas; a obtenção de um professor estrangeiro para atuação e formação de um quadro de profissionais no Brasil; e equiparação da Educação Física às outras disciplinas em importância.

Palavras chave: História. Brasil. Educação Física. Educação primária e secundária.
Recebido em: 29-06-2020 Aprovado em: 08-09-2020 Publicado em: 07-12-2020

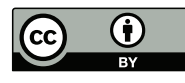

Este é um artigo publicado sob a licença Creative Commons Atribuição 4.0 Internacional (CC BY 4.0).

elSSN: $1982-8918$ 


\section{INTRODUÇÃO}

Rui Barbosa (1849 - 1923) foi um intelectual brasileiro com significativa importância no período transitório do Império para a República, contribuindo com diversos temas no seu tempo (MACHADO, 2002). Não obstante, poder-se-ia afirmar que a centralidade de suas elaborações giravam em torno de propostas para a modernização do Estado brasileiro, com a intenção de transformar a economia, até então predominantemente agrária, para um modelo industrial moderno que subsidiasse o avanço da nação (MACHADO; ARAÚJO, 2005).

Rui Barbosa foi estudado por diversos autores de diferentes áreas do conhecimento, fato que resultou em uma amplitude de visões acerca de suas obras, mas que, contudo, não esgotou suas contribuições. Ora classificado como idealista (MANGABEIRA, 1960; ORNELLAS, 1954; PALHA, 1954), por suas ideias abstratas; ora definido como realista (DELGADO, 1945; PIRES, 1949), por sua capacidade de organização e proposição de soluções aos problemas nacionais, o autor ainda figura como um intelectual de relevância no cenário político brasileiro.

Além de contribuições para o campo do Direito, das Relações Internacionais e das Ciências Políticas, Rui Barbosa visualizou, na instrução pública, potencial para as reformas pretendidas para o país e se estabeleceu como destacado intelectual para a compreensão do pensamento educacional brasileiro, com as primeiras publicações sobre o tema datadas do ano de 1873, em artigos sobre a reforma da instrução pública e posteriormente redigindo pareceres e proferindo discursos (BASTOS, 2000).

Assim, defendeu o papel do Estado na universalização da educação do jardim de infância até a universidade, com objetivo de oferecer acesso não só às elites, mas também às camadas populares. Ao analisar a educação pública das nações ditas por ele modernas, identificou no Brasil um latente estado de atraso.

Foi na crítica a um modelo de instrução pública elitizado e pautado pela retórica e memorização que Rui Barbosa, a partir do método intuitivo ${ }^{1}$, defendeu uma reforma no ensino que visava preparar crianças e jovens para a vida (MACHADO, 2002) e propôs mudanças necessárias à construção de um sistema nacional de ensino que contemplasse novos conteúdos, a saber: o desenho, a música, o canto, as ciências e a Educação Física (EF) no ensino primário.

No século XIX, o Brasil - e consequentemente a EF - passou a receber as primeiras influências dos métodos ginásticos europeus. Nesse contexto, a EF adquiriu relevância social, sobretudo a partir dos discursos médicos higienistas e das instituições militares, que conjuntamente apontavam os exercícios ginásticos como "remédio" aos males que afligiam a sociedade à época (SOARES, 2012). É neste contexto que emergem as primeiras proposições para o ensino da EF na instrução pública (BREGOLATO, 2002; MORENO, 2015; SOARES, 2000, 2012; VIGARELLO; HOLT, 2008).

Inserido no debate, Rui Barbosa defendeu publicamente a obrigatoriedade da disciplina EF no parecer denominado "Reforma do Ensino Primário e várias instituições

1 Inspirado em Comênio, Pestalozzi e Fröebel, o método se define, entre outras coisas, pela aprendizagem por meio do contato com as coisas sólidas e não com abstrações que distanciam os estudantes do aprendizado real. 
complementares da instrução pública" publicado no ano de 1883 , resultante de sua análise acerca do decreto $n^{\circ} 7.247$, de 19 de abril de 1879, concebido pelo então Ministro dos Negócios do Império, Carlos Leôncio de Carvalho. Em linhas gerais, no decreto constava a reforma do ensino primário e secundário no município da corte ${ }^{2}$. Trata-se de um parecer denso, detalhado e que apresentava a situação do ensino brasileiro contendo números calamitosos em relação às taxas de acesso à educação. Além disso, neste parecer, tem-se sua proposta de organização pedagógica para as escolas, caminhos para sua administração e direcionamentos à formação do professorado.

Apesar da existência de pesquisas que investigaram de diferentes formas e de modo acentuadamente diluído a visão de Rui Barbosa sobre a EF (MARINHO, 1954; OLIVEIRA, 1990; SOARES, 2000, 2012), cabe ressaltar que novos estudos devem ser realizados periodicamente para revisão crítica dos acúmulos, consensos e pressupostos do campo acadêmico-científico (BOURDIEU, 2004a, 2004b).

Além disso, em busca realizada no catálogo de Teses e Dissertações da Capes, identificou-se somente um estudo que se dedicou às contribuições de Rui Barbosa para o ensino da EF, nomeadamente a dissertação de mestrado defendida por Sérgio Henrique Gerelus, em 2007, com o objetivo de investigar a educação do corpo na reforma do ensino primário tal qual pensada por Barbosa. Também se buscou nos periódicos científicos circunscritos à área da $\mathrm{EF}^{3}$ a possível existência de artigos relacionados ao autor. Para tal, utilizaram-se os descritores "Rui Barbosa" OR "Ruy Barbosa4". Contudo, nenhum artigo foi encontrado. Tal fato, sem dúvida, justifica o investimento reflexivo proposto a partir dos escritos de Rui Barbosa para o campo acadêmico-científico da EF.

Em virtude dos fatos mencionados, objetivou-se nesta pesquisa identificar as influências e proposições para a EF apresentadas por Rui Barbosa em seu parecer para o ensino primário. Com efeito, pretende-se expor sua concepção sobre a EF e analisar em que medida tais concepções, embora historicamente situadas, podem ecoar no tempo, convergindo em reflexões atuais para o campo da EF. Noutras palavras, busca-se dar continuidade ao processo de qualificação dos estudos históricos da comunidade científica da EF, haja vista que, assim como sinalizou Melo (2008), é pertinente refletir sobre a história das práticas corporais institucionalizadas. A intenção é criar situações de estranhamento e chamar a atenção para possibilidades que passaram despercebidas, com novos objetivos e olhares para novas compreensões da fonte de pesquisa.

\footnotetext{
2 Do ponto de vista histórico, vale destacar o trabalho de Faria Filho (2017), que analisa as obras completas de Rui Barbosa.

3 Essa busca foi realizada em abril de 2020 nos periódicos com classificação entre A1 e B3 - Classificação do Qualis-Periódicos 2013-2016 - da área "Educação Física" com periodicidade em dia e que dialogassem com área sociocultural e pedagógica da EF. Logo, a busca foi realizada nos seguintes periódicos: Movimento; Motriz; Revista Brasileira de Ciências do Esporte (RBCE); Revista Brasileira de Educação Física e Esporte (RBEFE); Revista da Educação Física UEM; Pensar a Prática; Motrivivência; Revista Brasileira de Ciência e Movimento; e Licere.

4 A opção pela procura de ambos os nomes se fez necessária diante do fato de que alguns estudiosos tratam o autor como Ruy Barbosa e outros como Rui Barbosa. Isso se estabeleceu a partir da mudança do novo acordo ortográfico que modificou o nome de personalidades mortas. Originalmente, o autor denominava-se e assinava seu nome como Ruy Barbosa. A partir do novo acordo ortográfico o nome correto em concordância com as novas normas foi Rui Barbosa.
} 
20 PROCESSO METODOLÓGICO DE LEITURA E ANÁLISE DOS PARECERES

A busca por identificar as influências e proposições para a EF apresentadas por Rui Barbosa, em seu parecer para o ensino primário, caracterizou a presente pesquisa como qualitativa (CRESWELL, 2010), sobretudo, considerando a complexidade na compreensão dos documentos analisados e sua consequente interpretação.

A teoria que orientou as análises foi a Micro-história, caracterizada como uma abordagem da História Cultural (BURKE, 2005), inicialmente utilizada por Carlo Ginzburg na obra O queijo e os vermes (GINZBURG, 2006), na qual o autor narrou a história do julgamento de Domenico Scandella, chamado de Menocchio, um moleiro queimado por ordem do Santo Ofício. Apesar do objetivo de narrar o julgamento, o livro, a partir dos depoimentos de Menocchio, promoveu importantes reflexões sobre a Europa pré-industrial marcada pela difusão da imprensa e da Reforma Protestante. As análises realizadas por Ginzburg são fruto de um rigor na leitura dos depoimentos de Menocchio, que contribuem para a compreensão do pensamento do próprio Menocchio e do contexto social em que vivia. Posteriormente, e, mais especificamente, na década de 1970, a Micro-história se diversificou significativamente, com investigações voltadas para aldeias, indivíduos, famílias, conventos, badernas, assassinatos e suicídios (BURKE, 2005).

Neste sentido, a Micro-história (REVEL, 1998) emergiu a partir da preocupação com as análises dos fatos documentais, buscando identificar a representação real do documento, rompendo com generalizações e promovendo a investigação de fontes reduzidas para elaboração de conclusões acerca do momento histórico (LIMA, 2009). O ponto de partida dessa abordagem é o empirismo radical do corpus empírico de análise para, posteriormente, promover uma reconstrução totalizante, inferindo até que ponto os dados analisados impactaram sua realidade social (REVEL, 1998).

Tendo em vista o rigor relativamente aos fatos documentais analisados, orientados pela Micro-história, optou-se pelo uso da Análise de Conteúdo (BARDIN, 2016), que se caracteriza como "[...] um conjunto de técnicas de análise das comunicações, que utiliza procedimentos sistemáticos e objetivos de descrição de conteúdos [...]" (BARDIN, 2016, p. 38). Esta técnica é composta por três fases específicas: a Pré-análise; a Exploração do Material; e o Tratamento dos Resultados. Como ferramenta de apoio às análises, utilizou-se o software MAXQDA $\AA^{5}$, que auxilia na análise de dados não estruturados a partir de ferramentas específicas.

$\mathrm{Na}$ Pré-análise, selecionaram-se os documentos analisados: o parecer denominado "Reforma do Ensino Primário e várias instituições complementares da instrução pública"6 de 1883 apresentado por Rui Barbosa, em conjunto com o decreto $\mathrm{n}^{0} 7.247^{7}$, de 19 de abril de 1879, escrito pelo então Ministro dos Negócios

\footnotetext{
5 O MAXQDA é um software que oferece ferramentas de suporte para análise de dados qualitativos como textos, entrevistas, transcrições, gravações em áudio/vídeo, revisões de literatura etc. Disponível em: www.maxqda.com/ brasil. Acesso em: 29 jun. 2020.

6 As obras de Rui Barbosa foram organizadas em formato de tomos pela Fundação Casa de Rui Barbosa em 1947. Disponível em: http://docvirt.com/docreader.net/DocReader.aspx?bib=obrascompletasruibarbosa\&pagfis=6975. Acesso em: 29 jun. 2020.

7 BRASIL. Decreto $n^{\circ} 7.247$, de 19 de abril de 1879. Reforma o ensino primario e secundario no municipio da Côrte e o superior em todo o Imperio. Disponível em: https://www2.camara.leg.br/legin/fed/decret/1824-1899/decreto-724719-abril-1879-547933-publicacaooriginal-62862-pe.html. Acesso em: 29 jun. 2020.
} 
do Império, Carlos Leôncio de Carvalho. Os documentos foram importados para o software $M A X Q D A ®$, e iniciou-se o processo de leitura flutuante, com a intenção de estabelecer contato, deixando-se invadir por impressões para a condução de um esquema de análise.

$\mathrm{Na}$ Exploração do Material, os documentos foram categorizados internamente ao software MAXQDA®. O processo de categorização teve como objetivo classificar elementos constitutivos do texto com base em critérios previamente definidos e desenvolvidos a partir da Pré-análise, para a posterior obtenção simplificada dos dados brutos (BARDIN, 2016), os quais, por sua vez, estão alinhados aos objetivos da pesquisa.

Nesta etapa, estabeleceram-se duas categorias: "Influências" e "Proposições". Na categoria "Influências", formularam-se outras cinco subcategorias: "Grécia Antiga", "Fisiologistas", "Nações modernas", "Pensadores da educação", e "Pensadores da ginástica". Na categoria "Proposições", formularam-se as subcategorias: "Ginástica para ambos os sexos", "Seção de ginástica nas escolas", "Professor estrangeiro", e "Equiparação com outras disciplinas". As categorias "Influências" e "Proposições" foram elaboradas internamente ao documento que compunha o parecer de Rui Barbosa e o decreto de Carlos Leôncio de Carvalho ofereceu suporte à compreensão da subcategoria "Equiparação com outras disciplinas" interna à categoria "Proposições". $\mathrm{Na}$ imagem abaixo pode-se visualizar o transcurso da categorização internamente ao software MAXQDA®, a partir da ferramenta MaxMaps $®$ :

Figura 1 - Categorias e subcategorias elaboradas a partir do parecer "Reforma do Ensino Primário e várias instituições complementares da instrução pública" de Rui Barbosa e Decreto n 7.247 do Ministro dos Negócios do Império, Carlos Leôncio de Carvalho.

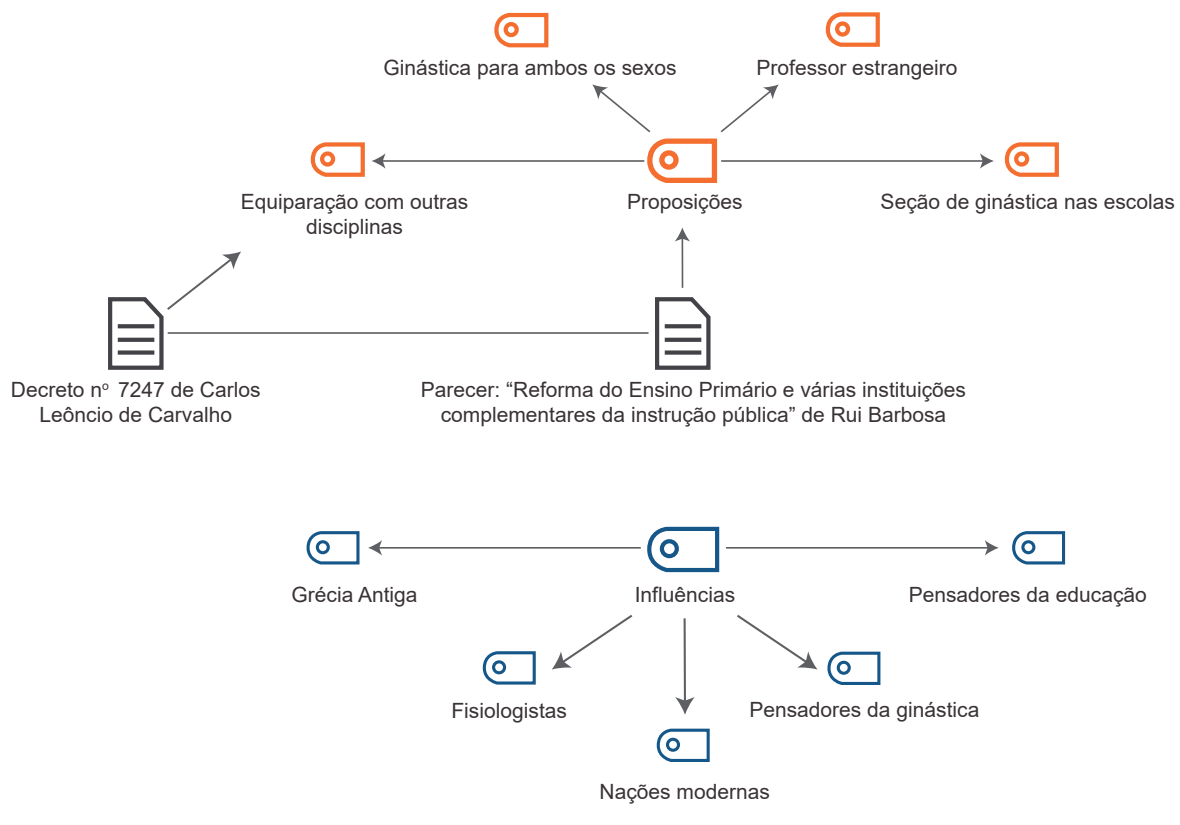

Fonte: Autoria própria.

Com a categorização finalizada, iniciou-se o processo de análise com sínteses, seleção dos resultados, interpretações e inferências sobre o documento. 
Para uma melhor compreensão da análise, faz-se necessária uma ressalva. Ao longo do texto, nas citações atinentes a Rui Barbosa, ora será utilizado o termo $E F$, ora ginástica. Para compreender essa questão e evitar equívocos, é importante salientar que, à época, o autor denominava a disciplina escolar de EF, mas alguns autores utilizavam somente o termo ginástica, como no caso do próprio Carlos Leôncio de Carvalho em seu decreto. Dado que no período em consideração a disciplina de EF resumia-se à ginástica, ambos os usos estão prescritos no parecer.

Todo o desenvolvimento analítico vai se pautar na metodologia aqui proposta. Primeiro, o diálogo será realizado a partir da categoria "Influências". Posteriormente, a categoria "Proposições" será analisada. Por fim, serão apresentadas reflexões acerca dos impactos do parecer naquele momento histórico à luz da Micro-história, que objetiva inferir até que ponto determinado corpus empírico de análise impactou sua realidade social (LEPETIT, 1998; REVEL, 1998; ROSENTAL, 1998), razão pela qual recorreu-se à literatura científica sobre o tema.

\section{RUI BARBOSA: INFLUÊNCIAS E PROPOSIÇÕES PARA A EDUCAÇÃO FÍSICA BRASILEIRA}

Ao apresentar a proposta para a EF, Rui Barbosa externalizou suas principais influências para a construção de seu parecer, resultantes da leitura de vasta literatura estrangeira do século XIX, cujo exemplo é a ampla biblioteca que constituiu ao longo de sua vida ${ }^{8}$.

A primeira influência tem origem nos escritos sobre a Grécia Antiga, para defender a disciplina internamente à instrução pública do período. Aquela civilização se preocupava com uma educação não só da mente, mas também do corpo, o que era um de seus traços dominantes (MARROU, 1969). No entendimento de Barbosa, "[...] o desenvolvimento inteligente do corpo era tido, em toda a Grécia, como um dos elementos essenciais de toda a educação liberal [...] os gregos [...] não concebiam espírito são em corpo enfermiço, alma serena sob um invólucro desestimado e lerdo" (BARBOSA, 1947, p.66).

É nesta civilização que o autor encontrou justificativa para uma educação do corpo que objetivava formar uma juventude sadia e sob a responsabilidade do Estado. As inspirações vindas da Grécia Antiga cimentaram suas proposições para a EF como uma disciplina obrigatória na instrução pública que, por lidar com o corpo, prepararia o trabalhador para o ofício, promovendo saúde e força em prol da produção evitando seu adoecimento, o que era um discurso característico dos liberais da época (MACHADO; ARAÚJO, 2005).

Outra influência significativa são os fisiologistas para justificar a importância da disciplina ao desenvolvimento integral dos indivíduos. Rui Barbosa se apropriou desses estudos para afirmar que o cérebro se desenvolve a partir de um duplo exercício: "[...] a ação consciente do cérebro, no pensamento (cerebração) e a ação inconsciente do cérebro dirigindo os movimentos do corpo" (BARBOSA, 1947, p.70). 
Ou seja, as atividades com o corpo se caracterizariam como uma ação inconsciente do cérebro, fato que auxiliaria no seu desenvolvimento integral, resultando em um estímulo diferente do que as outras disciplinas escolares promoviam.

Rui Barbosa apresentou também as nações modernas como influência, que para ele eram mais avançadas que o Brasil, já defendiam a EF na instrução pública e, "[...] ensinadas pela observação da realidade, vão de dia em dia ligando mais alto apreço a este elemento educador [...]" (BARBOSA, 1947, p. 68). A Europa, naquele momento histórico, assistia à valorização da ginástica na escola (MORENO, 2015), e não faltavam exemplos de países que a afixavam como disciplina obrigatória, cada qual com características específicas e diferentes métodos. O próprio Barbosa (1947, p. 75) afirmara: "Na Europa, hoje, não se pensa de outro modo" e são nessas nações que ele visualizou momento fértil para a defesa da disciplina no ensino primário, uma vez que nelas se inspirou para propor o acréscimo da EF no Brasil.

Sobre os pensadores da educação, houve menção a Antoine Aimé Riant, Émile Littré, Ralph Waldo Emerson, Émile Laveleye, Gabriel Compayré, Frederic Dittes, James Pyle Wickersham, Horácio Greeley, Henry Braudrillart e Herbert Spencer. Esses pensadores - cada qual a sua forma - se posicionaram em defesa de cuidados com o corpo na escola para o desenvolvimento da saúde e, remetendo a Horácio Greeley, Barbosa defendeu que "[...] a educação deve ter por alvo desenvolver a inteira natureza humana moral, intelectual e física [...]" (BARBOSA, 1947, p. 75) e alinhando-se com o que foi produzido sobre a educação no período, se balizou nesses pensadores para defender a EF internamente à instrução pública, em um contexto de crescente preocupação com o corpo por parte das elites (SOARES, 2012).

Por fim, no que concerne aos pensadores da ginástica, houve menção a Adolf Spiess, Eugéne Paz, Guts-Muths, Napoléon Laisné, Pehr Henrik Ling e R. Schenstrom, que criaram métodos de ensino no contexto europeu e eram valorizados em seus respectivos países. De um modo geral, esses pensadores visualizaram, na prática da ginástica, benefícios para os indivíduos, o que impactava, também, em benefícios para o Estado, fato que justificou sua importância social naquele contexto (BREGOLATO, 2002).

Nota-se, como pano de fundo de todas essas influências, os ideais médicohigienistas disseminados no pensamento corrente da sociedade brasileira e, consequentemente, da EF tal qual proposta no parecer, que adquiriu relevância social, baseada nesses ideais disseminados pela elite do país (SOARES, 2012). Neste sentido, no parecer, as ideias higiênicas não chegam a ser tratadas de forma tão clara quanto às ideias apresentadas pelos fisiologistas ou pelos pensadores da ginástica. Entretanto, a um olhar mais atento, tais ideias foram difundidas em todas as influências, desde os gregos antigos até os pensadores da educação, corroborando a noção segundo a qual o pensamento médico-higienista perpassava o pensamento de Rui Barbosa.

Com efeito, pode-se inferir que a EF proposta recebia as mais diversas influências. O diálogo que Rui Barbosa promoveu com a história, a partir da Grécia Antiga, com as ciências biológicas a partir dos fisiologistas, com as nações 
modernas que serviam de exemplos para o Brasil, com os pensadores da educação que defendiam a educação do corpo nas escolas, com os pensadores da ginástica valorizados em seus respectivos países, e tudo isso permeado por ideais médicoshigienistas, demonstra a riqueza de seu parecer.

O esforço realizado por Rui Barbosa é digno de reconhecimento, sobretudo por englobar quantidade expressiva de influências, demonstrando, desde aquele momento histórico, o que viria ser a EF no Brasil: um campo que estabelece relações com diversas ciências na sua formação, na sua prática e no desenvolvimento científico.

Todas essas influências expostas têm a intenção de cimentar suas proposições para a EF internamente ao ensino primário na época. Assim, como proposições, Barbosa defendeu inicialmente a obrigatoriedade da prática para ambos os sexos. Naquele momento histórico, incorria o debate acerca da possibilidade de a mulher realizar exercícios ginásticos, em um contexto que visualizava o corpo feminino por um viés biológico relacionado à maternidade (MOURÃO, 2000; SOARES, 2012). Envolto a este debate, Barbosa se posicionou e apresentou a necessidade da EF para ambos os sexos:

Assim, pois, todo o mundo civilizado, podemo-lo dizer, impõe hoje como necessidade vital, na organização da escola, a ginástica, ampliada aos dois sexos. A comissão, portanto, não tinha que vacilar em Ihe reconhecer o que, pela mais rigorosa das exigências racionais toca a esse ramo de ensino (BARBOSA, 1947, p. 90).

No que concerne ao que Rui Barbosa denominou como mundo civilizado as nações modernas -, a EF já figurava como disciplina obrigatória para ambos os sexos e os pensadores da ginástica, como Adolfo Spiess, Napoléon Laisné, Pehr Henrink Ling e Eugéne Paz, faziam tal defesa, apesar de existir distinções para o sexo feminino e o sexo masculino.

Para o sexo feminino, a EF compunha-se de exercícios com caráter "suave, acomodado ao sexo" (BARBOSA, 1947, p. 90), com enfoque na calistenia e baseados no método de Adolfo Spiess "[...] destinados a produzirem um simétrico desenvolvimento muscular, sem prejuízo da doçura das maneiras, da graça e elegância no talhe, da bela harmonia das formas femininas" (BARBOSA, 1947, p. 91).

Naquele período, era frequente a ideia, difundida pelos médicos higienistas, segundo a qual qualquer esforço exagerado empregado pela mulher resultaria em fraquezas, doenças e infertilidades das futuras gerações e, por isso, a EF para o sexo feminino adaptava-se à realidade da futura mãe, não sendo empregada de forma a promover excesso de esforço (MOURÃO, 2000).

Houve então no parecer a proposta de conectar o ensino da ginástica às mulheres com a música e o canto, uma vez que as autoridades europeias encontravam nessa combinação "[...] a racionalidade perfeita e a extraordinária utilidade da associação desses dois elementos na pedagogia escolar" (BARBOSA, 1947, p. 91). Essa ligação também tinha a influência da Antiga Grécia, onde "[...] a arte da música e da ginástica entrelaçavam-se inseparavelmente, a fim de preparar, de geração em geração, uma juventude sadia no corpo e na alma [...]" (BARBOSA, 
1947, p.67). Além disso, o ginasta Napoléon Laisné também defendeu tal junção e é citado no parecer em defesa da EF para o sexo feminino.

Já para o sexo masculino, a ginástica caracterizava-se pela junção com os exercícios militares e Rui Barbosa afirmou:

Ninguém nutre menos a tendência a militarização e de guerra do que nós. Mas a precisão, a decisão e a energia dos movimentos militares constituem, a par de um excelente meio de cultivo das forças corpóreas, um dos mais eficazes fatores na educação do caráter viril (BARBOSA, 1947, p. 91)

Em suma, o ensino popular tinha como um de seus objetivos "[...] preparar para a defesa da pátria" (BARBOSA, 1947, p. 91) e "seria, portanto, uma lacuna imperdoável a omissão dos exercícios militares num plano de reorganização do ensino popular [...] como meio de lançar nos hábitos da mocidade a base da defesa nacional [...]" (BARBOSA, 1947, p. 97). Tendo como referência as nações modernas, ainda afirmou: "Todas as nações que caminham à vanguarda da civilização moderna, teem-no reconhecido, estatuindo que a escola seja a primeira iniciadora do cidadão nas agruras da arte que o deve preparar para a defesa da pátria" (BARBOSA, 1947, p. 91).

Os pensadores da ginástica R. Schenstron e Pehr Henrik Ling também chamavam a atenção para o uso de exercícios militares na ginástica e Rui Barbosa se baseou neles, em conjunto com o pensador da educação Émile Laveleye, para defender o trato com esses exercícios para o sexo masculino internamente à instrução pública.

Essa preocupação com os exercícios militares é fundada principalmente em um contexto torneado por conflitos políticos e bélicos, que geravam uma tensão em escala mundial (MARTIN, 2009). Diversos países iniciaram um movimento em defesa desses exercícios nas escolas, preparando, cada vez mais cedo, soldados para seus exércitos.

Após a defesa da EF para ambos os sexos, cada qual com suas particularidades, Rui Barbosa propôs "[...] instituir, em cada escola normal, uma secção especialmente consagrada e esse ensino" (BARBOSA, 1947, p 97). Identifica-se a preocupação com o espaço físico para a prática da EF, que por se tratar de uma disciplina com diferentes características e necessidades, requeria mudanças arquitetônicas na escola para sua prática, preocupação essa que tem reverberações na EF atualmente. Diversas pesquisas identificaram que boa parte das escolas não têm espaço de qualidade para a disciplina e que professores ainda convivem com a necessidade de adaptação de espaços para sua prática (DAMAZIO; SILVA, 2008; MALDONADO; SILVA, 2016), demonstrando assim que a preocupação de Barbosa, naquela época, tem aplicabilidade nas atuais aulas de EF, ainda majoritariamente caracterizadas pela falta de estrutura física adequada.

Outra necessidade apresentada no parecer para a atuação nessas seções foi a obtenção "[...] por contrato, no estrangeiro, os serviços de alguma notabilidade ginasta, de algum dos ginasiarcas europeus de primeira ordem" (BARBOSA, 1947, p. 98). Como não havia professores para atuar com o tema, ele apontou a necessidade de contratação no estrangeiro, procurando em outros países profissionais capacitados 
para a atuação e formação, em um período em que ginástica deixa de ser atividade e passa a requerer formação técnica e intelectual (FIGUEIREDO; HUNGER, 2010).

Essa exigência de profissionais estrangeiros pode ser considerada como uma das primeiras defesas de uma formação específica para atuação com a $E F$, algo que no Brasil somente aconteceu em 1931, com a inauguração da Escola de Educação Física do Estado de São Paulo, que começa a funcionar em 1934 (SOUZA NETO et al., 2004).

Outra proposição defendida por Rui Barbosa diz respeito à equiparação da EF em grau de importância a outras disciplinas da escola primária por meio da "[...] inserção da ginástica nos programas escolares como matéria de estudo, em horas distintas das do recreio, e depois das aulas [...]" (BARBOSA, 1947, p. 98) e da "Equiparação, em categoria e autoridade, dos professores de ginástica aos de todas as outras disciplinas" (BARBOSA, 1947, p. 98). Tais afirmações discordavam do decreto $n^{\circ} 7.247$ de 19 de abril de 1979 proposto por Carlos Leôncio de Carvalho, no qual a ginástica se dava no recreio na "[...] pratica manual de officios e exercicios de gymnastica [....]" (BRASIL, 1879). Rui Barbosa ainda citou o exemplo da Alemanha e dos Estados Unidos como países que adotaram a EF em suas escolas e promoveram a equiparação da disciplina com outras.

Apesar de ter defendido a importância e igualdade da EF e de seus professores com as outras disciplinas, Rui Barbosa não poderia imaginar que, até hoje, a disciplina ainda luta por sua legitimação na escola para além dos aparatos legais e, por vezes, se vê marginalizada em detrimento a outras disciplinas (MALDONADO; SILVA, 2016), sendo somente em 1961, por meio da Lei n 4.024, considerada prática obrigatória nos cursos primários e médio e, posteriormente, com a Lei n 10.793, de 2003, considerada componente curricular obrigatório, reforçando a exigência legal da disciplina (BRASIL,1961; 2003).

Essas proposições estavam alinhadas a uma fração da elite brasileira, mais especificamente, a elite liberal, que se opunha à elite conservadora e escravista, preocupava-se com a educação - não só intelectual, mas também do corpo (SOARES, 2012) - e enxergava nela instrumento de transformação da sociedade (MACHADO, 2002; MACHADO; ARAÚJO, 2005). A elite liberal, naquele momento histórico, era vista como progressista com pautas voltadas para o fim da escravidão, a laicização do Estado e uma educação massificada para todos os estratos sociais (MACHADO, 2002; MACHADO; ARAÚJO, 2005), com a figura de Rui Barbosa como um de seus grandes exponenciais (MACHADO, 2002; SOARES, 2012).

As influências e proposições de Rui Barbosa demonstram como ele estava alinhado a diversos outros contextos, considerados por ele mais avançados que o Brasil. No período em que foi escrito - Segundo Reinado - era comum os intelectuais voltarem seus olhares para a Europa ou Estados Unidos em busca de soluções para a realidade brasileira a partir de uma nítida crise nacional (ALONSO, 2009). Não existia pedagogia ou ginástica brasileira e os pensadores da época vão beber de fontes que são exteriores ao Brasil diante de um país ainda em desenvolvimento (MACHADO, 2002; MACHADO; ARAÚJO, 2005; MORMUL; MACHADO, 2013). 
Ao analisar as propostas de Rui Barbosa para a EF, são nítidas as influências da Grécia Antiga, dos fisiologistas, das nações modernas, dos pensadores da educação, dos pensadores da ginástica e dos ideais médico-higienistas, mas, tudo isso, em conjunto com proposições materiais, para que a EF se configurasse como disciplina na instrução pública, inclusive com reflexões que até hoje, reverberou no campo da EF brasileira.

\section{IMPACTOS - OU NÃO IMPACTOS - DO PARECER DE RUI BARBOSA EM SEU MOMENTO HISTÓRICO}

Baseado na Micro-história, faz-se necessária a compreensão de até que ponto o parecer de Rui Barbosa impactou seu momento histórico (LEPETIT, 1998; REVEL, 1998; ROSENTAL, 1998). Isso faz emergir a necessidade de relatar que, apesar de todos os esforços para a promulgação de um sistema nacional de ensino, ele não chegou a ser discutido na Câmara dos Deputados (GERELUS, 2007; MACHADO, 2002) e, como relatou Barbosa, em uma das conversas com o Imperador do Brasil no parlamento, os pareceres "[...] entraram a dormir o sono donde passaram mofo e à traçaria dos arquivos [...]" (BARBOSA, 1942, p. 17-18).

Para entender a não discussão do parecer é necessário compreender o campo político no qual ele estava inserido. Um tema que torneava o debate era a questão da abolição e emancipação do escravo sexagenário. Esses assuntos eram vistos como prioridades pelos governantes, sobretudo pelos seus impactos econômicos. Logo, as questões educacionais que seriam debatidas não obtiveram a atenção necessária (MACHADO, 2002). Inclusive Rui Barbosa, em seus escritos, apresentou, na sua visão, um campo político desfavorável às reformas educacionais pretendidas por ele para o país (BARBOSA, 1942).

Outro elemento que ajuda a compreender a não discussão do parecer pode ser encontrado no estudo de Schelbauer (1998), que sistematizou os discursos sobre a educação no período de 1870 a 1914. A autora identificou que uma das razões pelas quais um sistema nacional de ensino não se efetivou, apesar de diversos personagens chamarem a atenção para esta necessidade, foi o fato de o campo político não dar a devida atenção à criação deste sistema, porque o motivo que inflamava a necessidade de sua criação, que era a formação de trabalhadores, com o passar do tempo esvaiu-se, diante do intenso processo migratório da Europa para - Brasil, fazendo com que o país recebesse imigrantes europeus para o trabalho nas lavouras e em outros ofícios, inibindo a necessidade de criação de um sistema escolar para a formação de trabalhadores (SCHELBAUER, 1998).

Não há como negar que havia políticos que defenderam a importância da educação e do investimento na instrução pública nos termos de Rui Barbosa que, inclusive, ao identificar o fracasso de seus pareceres, continuou a lutar pela implementação de algumas ideias do projeto e fundou a Liga do Ensino, que tinha como objetivo adotar métodos científicos na educação, melhorar as condições do professorado e estimular o ensino público laicizado (BASTOS, 2002), mas, no momento de discussão dos pareceres, o campo político jogou esse tema para 
escanteio, fato que resultou na criação de um sistema de ensino nacional somente na última década do século XIX e início do século XX.

Com base em todo esse contexto desfavorável, pode-se inferir que o parecer se configurou como uma representação das ideias circundantes acerca da EF naquele período, mas não se efetivou na instrução pública brasileira. Embora seu parecer não tenha sido discutido, é necessário reconhecer que ele estava voltado para um movimento geral e apontava para caminhos que o Brasil poderia tomar para acompanhar a sociedade em tempo de significativa transformação. Apesar disso, os contributos deixados pelo parecer ainda apresentam significativas reflexões para a EF nos dias de hoje.

\section{CONCLUSÃO}

O intuito desta pesquisa foi oferecer, a partir da Micro-história, novas chaves de leitura para o campo da EF brasileira com o objetivo de identificar as influências e proposições para a EF apresentada por Rui Barbosa em seu parecer para o ensino primário.

Neste sentido, pode-se identificar cinco influências para a EF no ensino primário: os gregos antigos e sua dupla educação, preocupando-se não só com a mente, mas também com o corpo; os fisiologistas e suas considerações sobre o funcionamento do cérebro, o que impactava no desenvolvimento do corpo; as nações modernas que se resumiam à grande parte da Europa e aos Estados Unidos, que efetivaram a EF na instrução pública do período; os pensadores educacionais que defendiam o trato com o corpo internamente à escola; os pensadores da ginástica, que eram valorizados na Europa a partir de seus métodos ginásticos e são inspirações para Rui Barbosa para o desenvolvimento da EF no Brasil. Todas essas influências são permeadas por ideais médico-higienistas.

No que concerne às proposições, constatou-se: a presença da ginástica para ambos os sexos, para a mulher, inspirada no método de Adolfo Spiess, ligada ao ritmo e ao canto que objetivava o desenvolvimento simétrico do corpo, mantendo a forma feminina, e para o homem, ligada a exercícios militares para a defesa da pátria; a criação de uma seção de ginástica nas escolas; a obtenção de um professor estrangeiro para a atuação e formação de um quadro de profissionais no Brasil; e a equiparação às outras disciplinas em importância. Todas essas proposições estavam alinhadas ao pensamento de uma fração da elite brasileira, mais especificamente, a elite liberal, que enxergava na educação - intelectual e do corpo - possibilidades de transformações na sociedade.

Apesar de situado naquele momento histórico, o parecer de Rui Barbosa oferece significativas reflexões para pensar a EF atualmente. Primeiro, pela quantidade de influências expostas, o que demonstra a lógica para a construção de uma EF não só pautada nas ciências biológicas, mas, também, nas pesquisas sobre a educação, em estudos históricos, em outros países e em diferentes métodos ginásticos. Todas essas influências demonstram o que viria a ser a EF hoje, caracterizada como um campo que estabelece relações com diversas ciências. Segundo, a preocupação com o espaço 
físico para a prática da EF, que reverbera até os dias atuais, com escolas que em significativa parte não contam com a estrutura necessária para que os professores realizem suas práticas pedagógicas. Por fim, a necessidade de equiparação da EF com outras disciplinas no contexto escolar, que ainda é marginalizada em relação as outras disciplinas mais valorizadas socialmente.

Se para Rui Barbosa "Felizmente, a causa da educação física está ganha, e a rotina pouco poderia retardar o seu triunfo em toda parte" (BARBOSA, 1947, p. 74), o mesmo não valia para o campo político brasileiro naquele momento. Assim como outros pareceres sobre a instrução pública no Império, ele não foi discutido na Câmara dos Deputados, pois as atenções voltavam-se para outras questões, como a abolição da escravidão, a emancipação do escravo sexagenário e a questão servil.

Fato é que Rui Barbosa é um homem de seu tempo e, diante de uma ainda incipiente EF no Brasil, avançou com contributos e problematizações que ecoam até hoje no nosso campo, com pareceres que proporcionam significativas reflexões e, por si só, demonstram a magnitude de seu pensamento.

\section{REFERÊNCIAS}

ALONSO, Angela. Apropriação de Idéias no Segunda Reinado. In: GRINBERG, Keila; SALLES, Ricardo (org.). Coleção O Brasil Império (1870-1889). Rio de Janeiro: Civilização Brasileira, 2009.

BARBOSA, Rui. Reforma do Ensino Secundário e Superior. Obras Completas. Rio de Janeiro: Ministério da Educação e Saúde, v. IX, t. I, 1942.

BARBOSA, Rui. Reforma do ensino primário e várias instituições complementares da instrução pública. Obras Completas. Rio de Janeiro: Ministério da Educação e Saúde, v. X, t. II, 1947.

BARDIN, Lawrence. Análise de Conteúdo. 6. ed. São Paulo: Edições 70, 2016.

BASTOS, Maria Helena Câmara. Ferdinand Buisson no Brasil - pistas, vestígios e sinais de suas idéias pedagógicas (1870-1900). Revista História da Educação. ASPHE/FaE/UFPel, v. 8 , p. $79-109$, set. 2000.

BASTOS, Maria Helena Câmara. Pro Patria Laboremus: Joaquim José de Menezes Vieira (1848-1897). Editora EDUSF: Bragança Paulista/SP, 2002.

BOURDIEU, Pierre. Os usos sociais da ciência: por uma sociologia do campo científico. São Paulo, SP: UNESP, 2004a.

BOURDIEU, Pierre. Para uma sociologia da ciência. Lisboa: Edições 70, 2004b.

BRASIL. Decreto $n^{\circ} 7.247$, de 19 de abril de 1879. Reforma o ensino primario e secundario no municipio da Côrte e o superior em todo o Imperio. Palácio do Rio de Janeiro, 19 abr. 1879. Disponível em: https://www2.camara.leg.br/legin/fed/decret/1824-1899/decreto-724719-abril-1879-547933-publicacaooriginal-62862-pe.html. Acesso em: 5 out. 2020.

BRASIL. Lei no 4.024, de 20 de dezembro de 1961. Fixa as diretrizes e bases da educação nacional. Diário Oficial da União, 27 dez. 1961. Disponível em: https://legislacao. presidencia.gov.br/atos/?tipo=LEl\&numero=4024\&ano=1961\&ato=339o3YU5keVRVT7a7. Acesso em: 29 jun. 2020. 
BRASIL. Lei no 10.793 , de $1^{\circ}$ de dezembro de 2003 . Altera a redação do art. 26 , $\S 3^{\circ}$, e o art. 92 da Lei no 9.394, de 20 de dezembro de 1996, que "estabelece as diretrizes e bases da educação nacional", e dá outras providências. Diário Oficial da União, 2 dez. 2003. Disponível em: http://www.planalto.gov.br/ccivil_03/leis/2003/L10.793.htm. Acessado em: 29 jun. 2020.

BREGOLATO, Roseli Aparecida. Cultura corporal da ginástica. São Paulo: Ícone, 2002.

BURKE, Peter. O que é história cultural? 2. ed. São Paulo: Zahar, 2005.

CARVALHO, Carlos Leôncio de. Reforma do Ensino Primário e Secundário do Município da Corte e o Superior em todo o Império do Brasil, 1879. p. 273-303.

CRESWELL, John W. Projeto de pesquisa: métodos qualitativo, quantitativo e misto. 3. ed. Porto Alegre: Artmed, 2010.

DAMAZIO, Marcia Silva; SILVA, Maria Fatima Paiva. O ensino da educação física e o espaço físico em questão. Pensar a Prática, v. 11, n. 2, p. 189-196, 2008. Disponível em: https://www.revistas.ufg.br/fef/article/view/3590. Acessado em: 29 jun. 2020.

DELGADO, Luiz. Rui Barbosa: tentativa de compreensão e síntese. Rio de Janeiro: José Olímpio, 1945.

FARIA FILHO, Luciano Mendes. Edição e sociabilidades intelectuais: a publicação das obras completas de Rui Barbosa (1930-1949). Belo Horizonte: Editora Autêntica; Editora UFMG, 2017.

FIGUEIREDO, Juliana Frâncica; HUNGER, Dagmar Aparecida Cynthia França. A relevância do conhecimento histórico das ginásticas na formação e atuação do profissional de Educação Física. Motriz. Revista de Educação Física, v. 16, n. 1, p. 189-198, 2010. Disponível em: https://repositorio.unesp.br/handle/11449/41150. Acesso em: 29 jun. 2020.

GERELUS, Sérgio Henrique. Rui Barbosa e a educação do corpo na reforma do ensino primário. 2007. Dissertação (Mestrado em Educação) - Programa de Pós-graduação em Educação, Universidade Estadual de Maringá, Maringá, 2007. Disponível em: http://www. dominiopublico.gov.br/pesquisa/DetalheObraForm.do?select_action=\&co_obra=119801. Acessado em: 29 jun. 2020.

GINZBURG, Carlo. O queijo e os vermes. São Paulo: Companhia de Bolso, 2006.

LEPETIT, Bernard. Sobre a escala na história. In: REVEL, Jacques (org.). Jogo de escalas: a experiência da microanálise. Rio de Janeiro: Fundação Getúlio Vargas, 1998. p. 77-102.

LIMA, Henrique Espada. Pensando as transformações e a recepção da micro-história no debate histórico hoje. In: OLIVEIRA, Mônica Ribeiro de (org.). Exercícios de microhistória. Rio de Janeiro: FGV, 2009. p. 131-154.

MACHADO, Maria Cristina Gomes. Rui Barbosa: Pensamento e ação. Rio de Janeiro: Autores Associados, 2002.

MACHADO, Maria Cristina Gomes; ARAÚJO, José Carlo de Souza. Metamorforses do pensamento liberal de Rui Barbosa: sua posição sobre Estado e Educação. Revista Diálogo Educacional, v. 5, n. 14, p. 1-12, 2005. Disponível em: https://periodicos.pucpr.br/ index.php/dialogoeducacional/article/viewFile/7367/7187. Acesso em: 29 jun. 2020.

MALDONADO, Daniel Teixeira; SILVA, Sheila A. dos Santos. Educação pública: a realidade da educação física na escola. Campinas: Mercado das Letras, 2016.

MANGABEIRA, João. O estadista da República. São Paulo: Martins, 1960. 
MARINHO, Inezil Penna. História da educação física e desportos. Rio de Janeiro: DEFMES,1954.

MARROU, Henri-Irénée. História da educação na antiguidade. São Paulo: Hucitec, 1969.

MARTIN, André. Guerra de sucessão. In: MAGNOLI, Demétrio (org.). História das guerras. 4. ed. São Paulo: Contexto, 2009. p. 189-218.

MELLO, Maria Lúcia Horta de Ludoff de; MENDONÇA, Lúcia Maria Velloso de Oliveira Rebello de. $\mathbf{O}$ arquivo histórico e institucional da fundação casa de Rui Barbosa. Rio de Janeiro: Ministério da Cultura; Casa de Rui Barbosa. 1997.

MELO, Victor Andrade de. Por uma História Comparada do Esporte: Possibilidades, Potencialidades e Limites. Movimento (Porto Alegre), v. 13, n. 3, p. 11-41, 2008.

Disponível em: https://seer.ufrgs.br/Movimento/article/view/3562. Acesso em: 29 jun. 2020.

MORENO, Andrea. A propósito de Ling, da ginástica sueca e da circulação de impressos em língua portuguesa. Revista Brasileira de Ciências do Esporte, v. 37, n. 2, p. 128-135, 2015. Disponível em: https://www.scielo.br/pdf/rbce/v37n2/0101-3289-rbce-37-02-0128.pdf. Acesso em: 29 jun. 2020.

MORMUL, Najla Mehanna; MACHADO, Maria Cristina Gomes. Rui Barbosa e a educação brasileira: os pareceres de 1882. Cadernos de História da Educação, v. 12, n. 1, p. $277-$ 294, 2013. Disponível em: http://www.seer.ufu.br/index.php/che/article/view/22909. Acesso em: 29 jun. 2020.

MOURÃO, Ludmila. Representação Social da Mulher Brasileira nas Atividades FísicoDesportivas: da segregação à democratização. Movimento (Porto Alegre), v. 6, n. 13, p. 5-18, 2000. Disponível em: https://seer.ufrgs.br/Movimento/article/view/11777. Acesso em: 29 jun. 2020.

OLIVEIRA, Vitor Marinho. O que é educação física? São Paulo: Brasiliense, 1990.

ORNELLAS, Archimino. Ruy Barbosa. Rio de Janeiro: Associação Atlética do Banco do Brasil, 1954.

PALHA, Américo. História da vida de Rui Barbosa. Rio de Janeiro: Casa de Rui Barbosa, 1954.

PIRES, Homero. Rui Barbosa e os livros. Rio de Janeiro: Casa de Rui Barbosa, 1949.

REVEL, Jacques. Microanálise e construção do social. In: REVEL, Jacques (org.). Jogo de escalas: a experiência da microanálise. Rio de Janeiro: Fundação Getúlio Vargas, 1998. p. 15-38.

ROSENTAL, Paul-André. Construir o "macro" pelo "micro": Frederik Barth e a "microstoria". In: REVEL, Jacques (org.). Jogo de escalas: a experiência da microanálise. Rio de Janeiro: Fundação Getúlio Vargas, 1998. p. 151-172.

SCHELBAUER, Analete Regina. Idéias que não se realizam: O debate sobre a educação do povo no Brasil de 1870 a 1914. Maringá: Editora da Universidade Estadual de Maringá, 1998.

SOARES, Carmen Lúcia. Notas sobre a educação no corpo. Educar em Revista, n. 16, p. 43-60, 2000. Disponível em: https://www.scielo.br/scielo.php?script=sci arttext\&pid=S0104-40602000000200004. Acesso em: 29 jun. 2020.

SOARES, Carmen Lúcia. Educação Física: raízes europeias e Brasil. 5. ed. Campinas, SP: Autores Associados, 2012. 
SOUZA NETO, Samuel de et al. A formação do profissional de educação física no Brasil: uma história sob a perspectiva da legislação federal no século XX. Revista Brasileira de Ciências do Esporte, v. 25, n. 2, p. 113-128, 2004. Disponível em: http://revista.cbce.org. br/index.php/RBCE/article/view/230. Acesso em: 29 jun. 2020.

VIGARELLO, George; HOLT, Richard. O corpo trabalhado - Ginastas e esportistas no século XIX. In: CORBIN, Alain; COURTINE, Jeanjacques; VIGARELLO, George (org.). História do corpo. 2. ed. Rio de Janeiro: Vozes, 2008. p. 393-478. 
Abstract: The study identifies influences and propositions for Physical Education presented by Rui Barbosa in his expert opinion on primary education. The documents analyzed were the opinion entitled "Reform of Primary School and Several Institutions complementary of Public Education," published in 1883, and Executive Order 7247 of April 19, 1879. The study was characterized as qualitative, with Microhistory as its guiding theory for the analyzes. It also employed Content Analysis. Five influences were identified: the ancient Greeks; physiologists; modern nations; education thinkers; and gymnastics thinkers. The following propositions were found: gymnastics for both sexes; creation of a gymnastics section in schools; bringing a foreign teacher to work and train professional staff in Brazil; and equating Physical Education with other disciplines in importance.

Keywords: History. Brazil. Physical Education. Education, primary and secondary.

Resumen: El objetivo del estudio fue identificar las influencias y propuestas para la Educación Física presentadas por Rui Barbosa en su informe para la educación primaria. Los documentos analizados fueron: el informe titulado "Reforma de la Educación Primaria y varias instituciones complementarias de la instrucción pública" publicado en 1883 y el decreto número 7.247, de 19 de abril de 1879. La investigación se caracterizó como cualitativa, tuvo la Microhistoria como teoría guía para los análisis y utilizó la técnica de Análisis de Contenido. Se pueden identificar cinco influencias: los antiguos griegos; fisiólogos; naciones modernas; los pensadores de la educación; y los pensadores de la gimnasia. En cuanto a las propuestas, se identificaron las siguientes: gimnasia para ambos sexos; la creación de una sección de gimnasia en las escuelas; tener un profesor extranjero para actuar en la formación y capacitación de un cuadro de profesionales en Brasil; y equiparar en importancia a la Educación Física a otras disciplinas.

Palabras clave: Palabras clave: Historia. Brasil. Educación física. Educación primaria y secundaria. 


\section{LICENÇA DE USO}

Este é um artigo publicado em acesso aberto (Open Access) sob a licença Creative Commons atribuição Não Comercial 4.0 (CC BY 4.0), que permite uso, distribuição e reprodução em qualquer meio, desde que o trabalho original seja corretamente citado, com a restrição que impede o uso para fins comerciais. Mais informações em: http://creativecommons.org/licenses/by/4.0

\section{CONFLITO DE INTERESSES}

Os autores declararam que não há conflito de interesses neste trabalho.

\section{CONTRIBUIÇÕES AUTORAIS}

Fernando Resende Cavalcante: Elaboração do texto - análises e escrita; Gabriel Carvalho Bungenstab: Elaboração do texto - análises e escrita; Ari Lazzarotti Filho: Elaboração do texto - análises e escrita.

\section{FINANCIAMENTO}

O presente trabalho foi realizado com apoio: da Coordenação de Aperfeiçoamento de Pessoal de Nível Superior - Brasil (CAPES) - Código de Financiamento 001 This study was financed in part by the Coordenação de Aperfeiçoamento de Pessoal de Nível Superior - Brasil (CAPES) - Finance Code 001; do Programa de Pós-graduação em Educação Física da Universidade de Brasília By the Graduate Program in Physical Education at the University of Brasilia; e da Fundação de amparo à pesquisa do Distrito Federal. By the Federal District Research Support Foundation.

\section{COMO REFERENCIAR}

CAVALCANTE , Fernando Resende; BUNGENSTAB, Gabriel Carvalho, LAZZAROTTI FILHO. Rui Barbosa e a educação física nos pareceres para o ensino primário de 1883: influências e proposições. Movimento, v. 26, p. e26078, jan./dez. 2020. Disponível em: https://seer.ufrgs.br/Movimento/article/view/104923. Acesso em: [dia] [mês abreviado]. [ano]. DOI: https://doi.org/10.22456/1982$\underline{8918.104923}$

\section{RESPONSÁVEIS EDITORIAIS}

Alex Branco Fraga*, Elisandro Schultz Wittizorecki*, Ivone Job*, Mauro Myskiw*, Raquel da Silveira*

*Universidade Federal do Rio Grande do Sul, Escola de Educação Física, Fisioterapia e Dança, Porto Alegre, RS, Brasil 